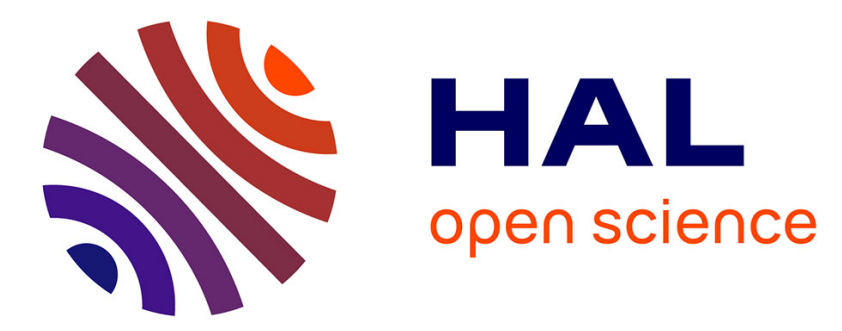

\title{
Loss analysis of Flyback in Discontinuous Conduction Mode for sub-mW harvesting systems
}

Armande Capitaine, Gaël Pillonnet, T Chailloux, Firas Khaled, Olivier Ondel, Bruno Allard

\section{- To cite this version:}

Armande Capitaine, Gaël Pillonnet, T Chailloux, Firas Khaled, Olivier Ondel, et al.. Loss analysis of Flyback in Discontinuous Conduction Mode for sub-mW harvesting systems. NEWCAS, Jun 2016, Vancouver, Canada. 10.1109/NEWCAS.2016.7604810 . hal-01317121

\section{HAL Id: hal-01317121 \\ https://hal.science/hal-01317121}

Submitted on 18 May 2016

HAL is a multi-disciplinary open access archive for the deposit and dissemination of scientific research documents, whether they are published or not. The documents may come from teaching and research institutions in France or abroad, or from public or private research centers.
L'archive ouverte pluridisciplinaire HAL, est destinée au dépôt et à la diffusion de documents scientifiques de niveau recherche, publiés ou non, émanant des établissements d'enseignement et de recherche français ou étrangers, des laboratoires publics ou privés. 


\title{
Loss analysis of Flyback in Discontinuous Conduction Mode for sub-mW harvesting systems
}

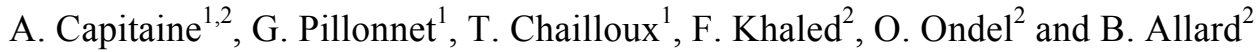 \\ ${ }^{1}$ Univ. Grenoble Alpes, F-38000 Grenoble, France CEA, LETI, MINATEC Campus, F-38054 Grenoble, France \\ ${ }^{2}$ Univ. de Lyon, INSA Lyon, Ampère, UMR CNRS 5005, F-69621 Villeurbanne, France
}

\begin{abstract}
This energy harvesting solution permits the autonomous supply of low power sensor nodes, without a chemical battery, allowing their extensive use in various environments. The electrical interface between the harvester and the sensor is crucial in order to maximize the harvested energy and boost the voltage to a minimum value required by the sensor. To achieve input impedance and voltage gain independently, this paper presents a flyback converter in discontinuous mode. Using the proposed flyback model validated experimentally, we have studied the impact of each loss source in order to give some trade-off for designing an efficient sub-mW harvesting interface. We underline the effect of the transformer losses due to the magnetic hysteresis as well as the driving loss impact. Following this method, the flyback prototype achieves $71 \%$ power efficiency when harvesting from a microbial fuel cell delivering $90 \mu \mathrm{W}$.
\end{abstract}

Keywords-flyback design method; energy harvesting; DC-DC converter; maximum power point tracking; microbial fuel cell

\section{INTRODUCTION}

Harvesting energy from the surrounding environment is an excellent alternative to conventional batteries for powering autonomously remote sensors in addition to processing in an eco-friendly way. Much research currently focuses on harvesting energy from solar, thermal and vibrational sources scavenged from the environment near the sensor. The microbial fuel cell (MFC), although less analyzed in the literature, is a new harvesting technology that exploits the waste materials around the sensor. The catalytic properties of bacteria in some redox reactions can convert chemical energy from a large range of carbonate substrates such as seafloor sediment or compost into electrical energy [1,2]. This energy production is relatively robust and low-cost. However the generated power is around $100 \mu \mathrm{W}$ for cm-scale electrodes and its DC voltage is insufficient e.g. up to $0.7 \mathrm{~V}$ to power continuously low-power sensor nodes. Therefore, to adapt and store the power generated by the harvester to the sensor, a harvesting interface is required i.e. a DC-DC converter. It has a two-fold objective: i) extract the maximum power from the harvester and ii) boost and regulate the voltage in an intermediate energy storage. Then, the sensor switches between on- and off-states depending on the energy available in this storage. The boost topology is commonly chosen for the harvesting interface $[3,4]$. However, this architecture suffers from an inherent limitation which is that the maximal power extraction point and voltage gain cannot both be satisfied in one conversion stage even in discontinuous conduction mode. To overcome this limitation, [4] adds a second stage to adapt the voltage gain independently to the input impedance. However, this two-stage conversion topology limits the achievable efficiency.

[5] proposes to use a flyback in discontinuous conduction mode (DCM) to overcome the limitation of the classical boost converter topology and also offer galvanic isolation adding value in some MFC applications. This work was done for an input power of $10 \mathrm{~mW}$. Our paper proposes the study of this topology for a sub-mW power range and presents a design methodology by analyzing each power loss source especially the transformer. The first section briefly presents the harvester electrical model and explains the flyback operation in DCM to show its ability to adapt its input impedance and voltage gain independently. Then, the trade-off for maximizing the power extraction from a sub-mW power source and optimizing the converter efficiency are explained. To help the designer in their choice e.g. transistor sizing, transformer or other components choices, a complete model of the flyback has been given and experimentally validated.

\section{FLYBACK CONVERTER FOR MFC ENERGY HARVESTING}

\section{A. Harvester electrical model and MPPT}

Solar, thermal and biofuel cell harvesters are often modeled by a voltage source $V_{S}$ and a series resistance $R_{S}$ (Fig. 1) when operating close to their maximum power point MPP [6]. Identifying these two parameters is a crucial step in determining the impedance value $R_{I N}$ of the harvesting interface and so optimizing the power extraction from the harvester. In fact, the power received by the harvesting interface is maximized when $R_{I N}$ is equal to $R_{S}$ and is expressed at the MPP as:

$$
P_{M P P}=\frac{V_{S}^{2}}{4 R_{S}}
$$

We define the extraction efficiency $\eta_{\text {extr }}$ as the ratio of the power delivered to the harvesting interface $P_{I N}$ over the maximum power the MFC can deliver $P_{M P P}$. $\eta_{\text {extr }}$ is equal to unity when the impedance matching is respected. In the case of our MFC prototypes [7], the MPP is $90 \mu \mathrm{W}$ at $0.3 \mathrm{~V}$ and their static behavior can be modeled with $\mathrm{V}_{\mathrm{S}}=0.6 \mathrm{~V}$ and $\mathrm{R}_{\mathrm{S}}=1 \mathrm{k} \Omega$.

The power generated by the MFC cannot be directly used to continuously power low-power sensor node. Therefore, a harvesting interface is necessary to boost the harvester output voltage $\mathrm{V}_{\text {IN }}$ to a minimum voltage $\mathrm{V}_{\text {OUT }}$ required to supply the 
sensor node. The chosen interface must have a global efficiency close to unity regarding the low power at stake. The global efficiency includes the extraction efficiency $\eta_{\text {extr }}$ and the PMU conversion efficiency $\eta_{\text {conv }}$ (equation (2), Fig. 1) where the latter is the ratio of the power delivered by the harvesting interface $\mathrm{P}_{\text {OUT }}$ over $\mathrm{P}_{\mathrm{IN}}$.

$$
\eta_{\text {extr }} \times \eta_{\text {conv }}=\frac{P_{I N}}{P_{M P P}} \times \frac{P_{\text {OUT }}}{P_{I N}}=\frac{P_{\text {OUT }}}{P_{M P P}}
$$

Moreover, since the MFC performance depends on the environment and $R_{S}$ varies, the MPP has to be regularly recorded to allow a dynamic impedance matching i.e. to continuously adapt the impedance $\mathrm{R}_{\mathrm{IN}}$ of the harvesting interface.

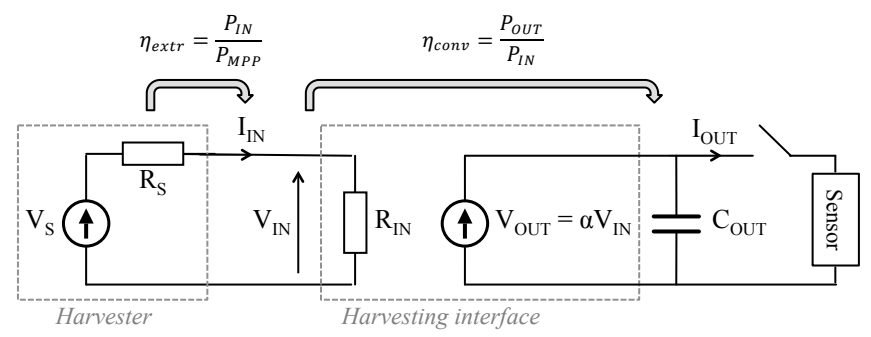

Fig. 1. Harvester electrical model and harvesting interface schematic.

\section{B. Flyback converter as harvesting interface}

The harvesting interface is commonly realized with a DC-DC converter. The flyback converter working under DCM is chosen. Its input impedance $\mathrm{R}_{\mathrm{IN}}$ can be dynamically adapted to $R_{S}$ by controlling the switching frequency $f$, without impacting on the voltage gain $\alpha$ (Fig. 1). Therefore, both conditions i.e. MPPT and output voltage regulation can be respected at the same time. The DCM also reduces the conduction losses in the converter because of the lower average input current. Moreover, the flyback offers a galvanic isolation between the input and output with its two coupled inductors.

The flyback structure is shown in Fig. 2. DCM operation imposes three phases. In the first phase, the MOSFET is closed and the current in the primary inductance $I_{1}$ increases quasi-linearly until a certain $\mathrm{I}_{1}$ MAX. The current in the secondary side $\mathrm{I}_{2}$ is blocked by the diode. In the second phase, the MOSFET is open and the energy stored in the primary inductance during phase 1 is transferred to the secondary side. Considering an ideal transformer conversion ratio of $1: 1$, the output current $I_{2}$ is equal to $I_{1 \_ \text {MAX }}$ at the beginning of phase 2 and decreases quasi-linearly. Phase 3 starts when $\mathrm{I}_{2}$ reaches zero and ends when phase 1 is reinstated. An input capacitance $\mathrm{C}_{\mathrm{IN}}$ is set to obtain a quasi-constant input voltage $\mathrm{V}_{\mathrm{IN}}$ and to smooth the current $\mathrm{I}_{\mathrm{IN}}$ delivered by the harvester. Regarding the input current waveform, the flyback impedance can be expressed by equation (3). Supposing the duty cycle D and the primary inductance $\mathrm{L}_{1}$ are fixed, the MPPT is handled by varying the frequency accordingly to the MFC impedance $R_{S}$ fluctuations without changing the voltage gain $\alpha$.

$$
R_{I N}=\frac{2 L_{1} f}{D^{2}}
$$

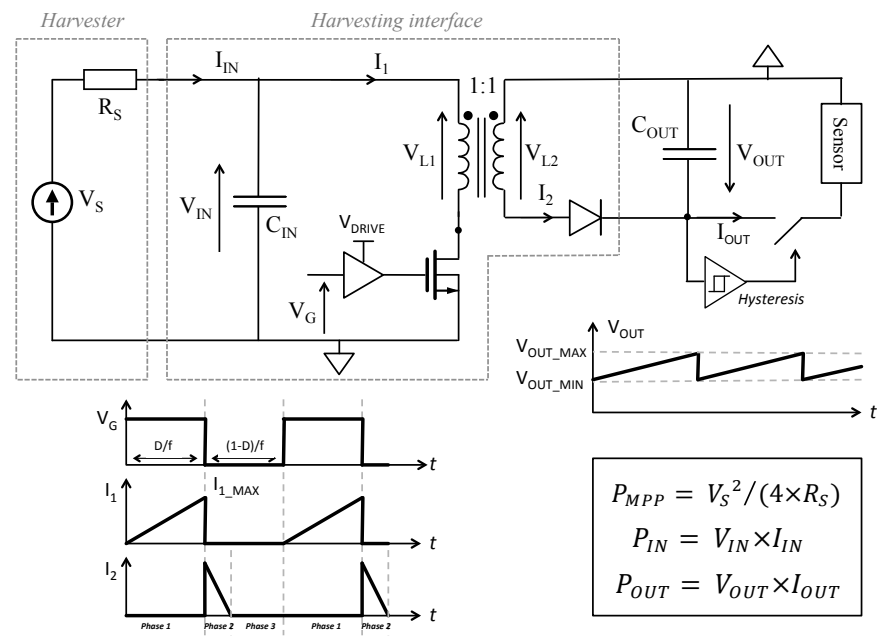

Fig. 2. Flyback converter working in DCM as harvesting interface.

At the output, the energy is stored in a capacitance $\mathrm{C}_{\text {OUT }}$ and is intermittently delivered to the sensor using a hysteresis comparator, shown in Fig. 2, making the output voltage oscillate between two values $\mathrm{V}_{\text {OUT_MAX }}$ and $\mathrm{V}_{\text {OUT_MIN }}$ where the latter is the minimal voltage required by the sensor. As the switch is open, energy is being stored in $\mathrm{C}_{\text {OUT }}$ and so $\mathrm{V}_{\text {OUT }}$ increases. When it reaches $\mathrm{V}_{\text {OUT_MAX }}$ the switch closes until $\mathrm{V}_{\text {OUT }}$ reaches $\mathrm{V}_{\text {OUT MIN }}$. $\mathrm{C}_{\text {OUT }}$ is chosen so that the amount of energy stored in one cycle corresponds to the energy $\mathrm{E}_{\text {sensor_cycle }}$ required by one complete cycle of the sensor (equation (4)).

$$
C_{O U T}=\frac{2 E_{\text {Sensor } \_y c l e}}{V_{O U T_{M A X}}{ }^{2}-V_{O U T_{M I N}}{ }^{2}}
$$

\section{Origin of the flyback power losses}

Determining the origin of the power losses in the converter is very important. Regarding the working conditions and electrical devices, the conversion efficiency can be extremely poor especially as the power delivered by our MFCs is less than $100 \mu \mathrm{W}$. The different power losses of the flyback due to the MOSFET and diode are given in Table. I, considering an ideal transformer with a conversion ratio of 1:1. The MOSFET presents an on-state resistance $\mathrm{R}_{\mathrm{ON}}$ causing conduction losses during phase 1 and an internal capacitance $C_{O S S}$ causing switching losses. The diode presents a threshold voltage $\mathrm{V}_{\mathrm{D}}$ causing conduction losses during phase 2 and a parasitic capacitance $C_{D}$. Although less studied, the transformer induces non-negligible losses in the flyback especially in sub-mW operation. In the next section, the transformer losses will be modeled in a compact electrical circuit allowing some tradeoff between all the flyback losses.

TABLE I. F LYBACK POWER LOSSES

\begin{tabular}{|c|c|c|}
\hline & Conduction losses & Switching losses \\
\hline MOSFET & $R_{\text {ON }} \frac{V_{S}{ }^{2}}{3 D R_{S}{ }^{2}}$ & $\frac{1}{2} C_{\text {OSS }}\left(\frac{V_{S}}{2}+V_{\text {OUT }}\right)^{2} f$ \\
\hline Diode & $\frac{V_{D} V_{S}{ }^{2}}{4 V_{\text {OUT }} R_{S}}$ & $\frac{1}{2} C_{D}\left(\frac{V_{S}}{2}+V_{\text {OUT }}\right)^{2} f$ \\
\hline
\end{tabular}




\section{FLYBACK DESIGN AND MODELLING}

\section{A. Component choices}

The choice of MOSFET is important because it can induce conduction losses with $\mathrm{R}_{\mathrm{ON}}$ and switching losses with $\mathrm{C}_{\mathrm{OSs}}$. Reducing one (for instance reducing $\mathrm{R}_{\mathrm{ON}}$ by increasing the drain-source channel width) generally increases the other (increasing $\mathrm{C}_{\mathrm{OSS}}$ ). We confirmed this by using the $\mathrm{N}$-channel MOSFET FDV301N [8] which was a good tradeoff for sub$\mathrm{mW}$ operation. Its threshold gate voltage is $1 \mathrm{~V}$ and it has a capacitance $\mathrm{C}_{\mathrm{OSS}}$ in the order of $90 \mathrm{pF}$, an $\mathrm{R}_{\mathrm{ON}}$ of $3.5 \Omega$ and a total gate charge $\mathrm{Q}_{\mathrm{g}}$ of $150 \mathrm{pC}$ when operating with a $\mathrm{V}_{\mathrm{G}}$ equal to $1.5 \mathrm{~V}$.

The BAT54 diode [9] was chosen because of its threshold voltage (lower than $0.3 \mathrm{~V}$ ) and low parasitic capacitance $C_{D}$ of $10 \mathrm{pF}$, thus minimizing the conduction losses in the secondary branch of the flyback as well as the switching losses.

\section{B. Parameter choices}

The input capacitance $C_{\mathrm{IN}}$ is used to maintain a DC voltage at the input of the flyback. According to equation (5), its value has to be sufficiently large in order to ensure a negligible input ripple $\Delta \mathrm{V}_{\mathrm{IN}}$. We chose to set $\Delta \mathrm{V}_{\mathrm{IN}}$ equal to $1 \%$ of $\mathrm{V}_{\mathrm{IN}}$.

$$
C_{I N}=\frac{V_{I N}}{\Delta V_{I N}} \times \frac{(2-D)^{2}}{4 R_{S} f}=100 \times \frac{(2-D)^{2}}{4 R_{S} f}
$$

The output voltage is set to oscillate around $1.8 \mathrm{~V}$ with a $\Delta \mathrm{V}_{\text {OUT }}$ of $0.1 \mathrm{~V}$.

If we suppose that the transformer conversion ratio is equal to 1 , then the duty cycle $\mathrm{D}$ has to be minimized to keep the flyback in DCM as given in equation (6), and maximized to avoid a large $\mathrm{I}_{1 \_ \text {MAX }}$ that may drive the transformer to magnetic field saturation and also induce large conduction losses in the switch. Setting the duty cycle D to 0.5 is therefore a good tradeoff.

$$
\frac{D}{1-D} \leq \frac{1}{\sqrt{\mathrm{y}_{\text {conv }}}} \times \frac{V_{O U T}}{V_{I N}}
$$

The switching frequency $\mathrm{f}$ and the transformer primary inductance $\mathrm{L}_{1}$ offer a certain degree of design freedom. To respect the MPP condition given by equation (3), the $\left\{L_{1} ; f\right\}$ couple is fixed i.e. increasing $\mathrm{L}_{1}$ means decreasing $\mathrm{f}$. Considering the MFC resistance obtained in section 2 $\left(\mathrm{R}_{\mathrm{S}}=1 \mathrm{k} \Omega\right)$, the influence of $\mathrm{L}_{1}$ i.e. $\mathrm{f}$ on the conversion efficiency $\eta_{\text {conv }}$ of the flyback converter was evaluated, without considering the driving loss. The result is the blue curve in Fig. 3. When the inductance is too small (i.e. the frequency is high), the switching losses are mainly due to the fact that MOSFET parasitic capacitance prevails and greatly reduces the flyback efficiency. This result therefore encourages the choice of a frequency close to zero. However, a tradeoff has to be made to avoid the use of a too large transformer in order to limit the circuit to a certain small size.

Our study only considers the MOSFET and diode losses. We will now focus on describing the parasitic aspects that can be encountered in a real transformer and the impact they can have on the conversion efficiency $\eta_{\text {conv }}$.

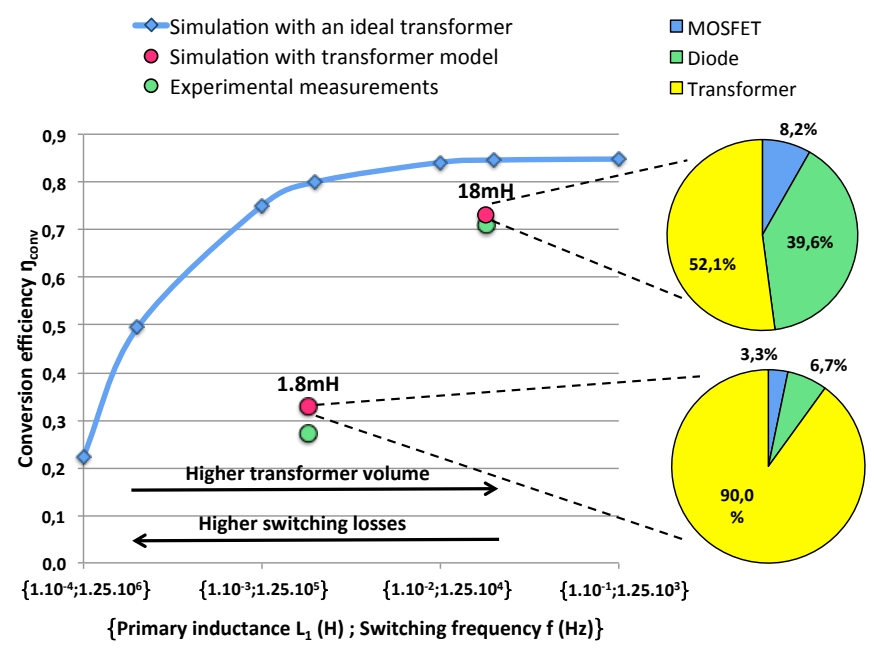

Fig. 3. Influence of the transformer primary inductance on the flyback conversion efficiency when working at the MPP with an ouput voltage of $1.8 \mathrm{~V}$ and without considering the driving losses.

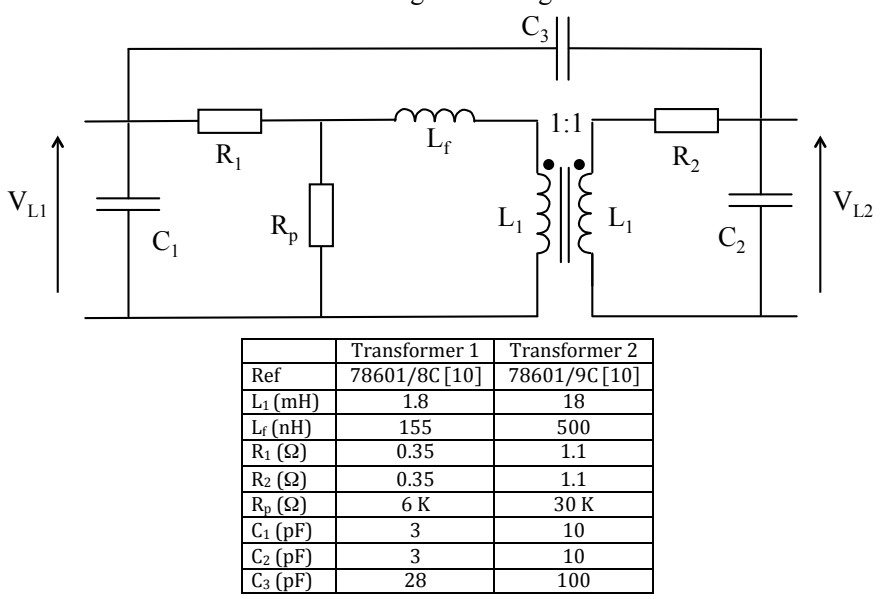

Fig. 4. Transformer electrical model.

\section{Transformer modelisation}

The choice of $\mathrm{L}_{1}$ is crucial. Regarding the variation of the harvester resistance $R_{S}, L_{1}$ will determine the frequency range according to the MPPT strategy and thus will greatly influence the conversion efficiency. In order to understand its impact on the conversion efficiency $\eta_{\text {conv }}$, an electrical model is required. Fig. 4 represents the equivalent electrical circuit of a $1: 1$ transformer with a primary inductance $\mathrm{L}_{1}$. The copper losses in the primary and secondary side are modeled with $R_{1}$ and $R_{2}$, the core losses mainly due to the hysteresis of the magnetic material are modeled by $\mathrm{R}_{\mathrm{P}}$, the leakage currents by $\mathrm{L}_{\mathrm{f}}$, the inter-winding capacitances in the primary and secondary with $\mathrm{C}_{1}$ and $\mathrm{C}_{2}$, and the capacitance between the primary and the secondary by $\mathrm{C}_{3}$.

Two transformers from the same manufacturer [10] that are typically used for energy harvesting applications were characterized in order to compare them on the same basis with different $\mathrm{L}_{1}$ leading to two switching frequencies. The transformers were characterized using a network analyzer with a frequency range of $[5 \mathrm{~Hz} ; 30 \mathrm{MHz}$. The values obtained for both of the characterized transformers (Fig. 4) were evaluated using the modeling strategy described in [11]. 


\section{EXPERIMENTAL VALIDATION}

\section{A. Transformer model validation and transformer losses}

The flyback was simulated by adding the model of each transformer and comparing it to the experimental data. The impedance was accurately matched i.e. the extraction efficiency $\eta_{\text {extr }}$ is equal to unity. The conversion efficiencies are represented in Fig. 3 and highlight an adequate fit between the simulated performances and those acquired experimentally. Our flyback electrical models can thus be considered reliable.

If we take into consideration the previous results with an ideal transformer (blue curve in Fig. 3), the addition of the transformer parasitic elements considerably decreases the converter conversion efficiency. This indicates that the transformer could be the bottleneck to increasing the harvested power efficiency. A previous study on the impact of each transformer parasitic element revealed that the parallel resistance $R_{P}$ representing the magnetic loss induces the majority of the transformer losses. This explains the greater losses of the $1.8 \mathrm{mH}$ transformer having a parallel resistance five times smaller $(6 \mathrm{k} \Omega)$ than the $18 \mathrm{mH}$ transformer $(30 \mathrm{k} \Omega)$.

\section{B. Driving losses}

To ensure a self-sufficient process, part of the flyback output power has to be used to supply the MOSFET driver. The power used to supply the sensor is thus $\mathrm{P}_{\text {OUT }}-\mathrm{P}_{\mathrm{G}}$ where $\mathrm{P}_{\mathrm{G}}$ is the power consumed by the MOSFET driver expressed by:

$$
P_{G}=Q_{g} V_{G} f
$$

We define the efficiency $\eta_{\text {Supply }}$ expressed by equation (8), as the ratio of the power available to supply the sensor $\mathrm{P}_{\text {OUT }}-\mathrm{P}_{\mathrm{G}}$ over the maximum power delivered by the MFC $\mathrm{P}_{\mathrm{MPP}}$.

$$
\eta_{\text {Supply }}=\frac{P_{\text {OUT }}-P_{G}}{P_{M P P}}=\frac{\eta_{\text {extr }} \eta_{\text {conv }} P_{M P P}-P_{G}}{P_{M P P}}
$$

Fig. 5 shows the influence of the driving losses on the power efficiency. The blue curve represents the conversion efficiency $\eta_{\text {conv }}$ previously shown in Fig. 3 without considering $\mathrm{P}_{\mathrm{G}}$. The yellow curve represents $\eta_{\text {Supply }}$ with an ideal transformer that includes the additional driving losses $\mathrm{P}_{\mathrm{G}}$ and highlights the available power given to the sensor. We observed that the smaller $\mathrm{L}_{1}$, the higher $\mathrm{f}$ and the higher the driving losses $\mathrm{P}_{\mathrm{G}}$.

The red dots are the supply efficiency $\eta_{\text {Supply }}$ simulated with the two previously characterized transformer models and the green dots are the data acquired experimentally which fit the simulation well. Using the $18 \mathrm{mH}$ transformer, $\eta_{\text {Supply }}$ reaches $71 \%$. The MPPT is respected and $\eta_{\text {extr }}$ is equal to unity. Considering an input power of $90 \mu \mathrm{W}$, the power that can be used by the sensor is $64 \mu \mathrm{W}$. The transformer induces almost $50 \%$ of the total losses. Hence, to further enhance the flyback performance, the design has to focus on choosing an adapted transformer with very few magnetic losses and an appropriate switching frequency.

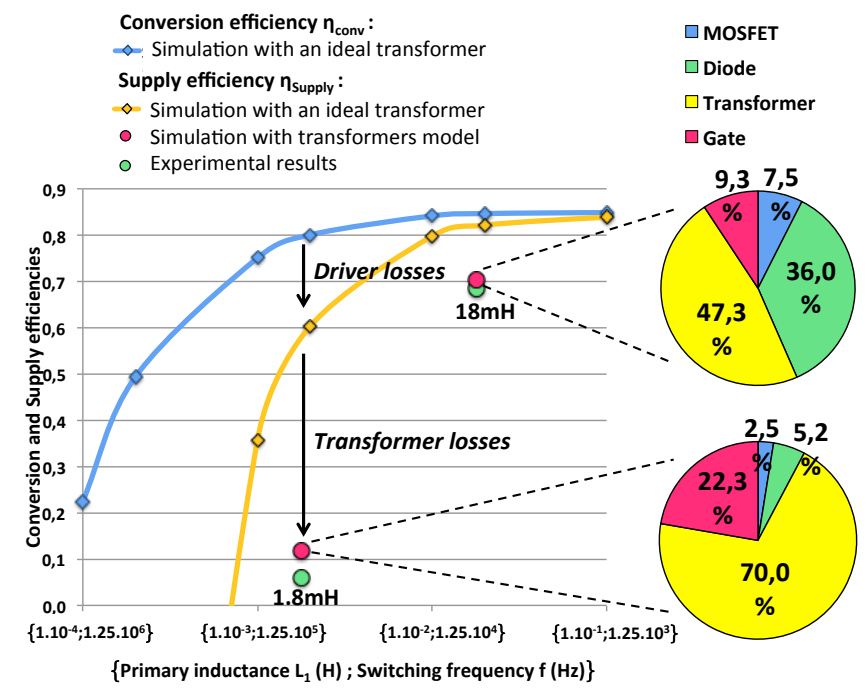

Fig. 5. Influence of all the losses onto the flyback efficiency.

\section{CONCLUSION}

In this paper, we analyzed in detail the losses of the flyback working in DCM for sub-mW harvesting applications. Using the proposed flyback model validated experimentally, we highlighted the impact of the transformer hysteresis losses on the power efficiency and the need to carefully choose the transformer. By choosing a good tradeoff between the switching frequency and the transformer, a prototype was able to transfer $71 \%$ of the $90 \mu \mathrm{W}$ maximum power available in the harvester to the sensor with an output voltage of $1.8 \mathrm{~V}$.

For more in-depth analysis, other transformers will be studied in the future.

\section{REFERENCES}

[1] V. Kiran, B. Gaur, "Microbial Fuel Cell: technology for harvesting energy from biomass", Reviews in Chemical Engineering. Volume 29, Issue 4, Pages 189-203, Aug. 2013.

[2] S. Venkata Mohan and al. "Microbial fuel cell: Critical factors regulating bio-catalyzed electrochemical process and recent advancements", Renewable and Sustainable Energy Reviews, 2014.

[3] H. Wang, J.-D. Park, et Z. Ren, "Active Energy Harvesting from Microbial Fuel Cells at the Maximum Power Point without Using Resistors", Environ. Sci. Technol., vol. 46, nº 9, p. 5247-5252, 2012.

[4] J.-D. Park et Z. Ren, "Hysteresis controller based maximum power point tracking energy harvesting system for microbial fuel cells “, Journal of Power Sources, vol. 205, p. 151-156, 2012.

[5] F. Khaled, B. Allard, O. Ondel, C. Vollaire, "Autonomous Flyback Converter for Energy Harvesting from Microbial Fuel Cells", Energy Harvesting and Systems. Nov. 2015

[6] S. Bandyopadhyay and al, "Platform Architecture for Solar, Thermal, and Vibration Energy Combining With MPPT and Single Inductor," IEEE Journal of Solid-State Circuits, vol. 47, no.9, pp.2199-2215, 2012.

[7] T. Chailloux and al. "Autonomous sensor node powered by $\mathrm{cm}$-scale benthic microbial fuel cell and low-cost and off-the-shelf components", Energy Harvesting and Systems EHS, 2016, in press.

[8] Datasheet of Fairchild Semiconductor, FDV301N Digital FET.

[9] Datasheet of Vishay Semiconductors, BAT54.

[10] Datasheet of muRata, 786 Series, General Purpose Pulse Transformers.

[11] F. Blache, "Modélisation électronique et électromagnétique d'un transformateur haute fréquence à circuit magnétique en fonte", $\mathrm{PhD}$ thesis, Institut National Polytechnique de Grenoble, 1995. 